ORIGINAL ARTICLE

\title{
Performance enhanced headgear: a scientific approach to the development of protective headgear
}

\author{
A McIntosh, P McCrory, C F Finch
}

Br J Sports Med 2004;38:46-49. doi: 10.1136/bjsm.2002.003103

See end of article for authors' affiliations

....................

Correspondence to: Dr Mclntosh, School of Safety Science, University of New South Wales, Sydney, NSW 2052, Australia; a.mcintosh@ unsw.edu.au

Accepted 31 January 2003

Background: There is a continuing debate about the performance of protective headgear in rugby union, rugby league, and Australian rules football.

Objectives: To examine the impact energy attenuation performance of foam that could be incorporated into headgear and examine the performance of prototypes of modified headgear.

Methods: Impact tests were conducted on polyethylene foams and protective headgear. Free fall drop tests with a rigid headform on to a flat rigid anvil were conducted. Resultant headform acceleration was measured. Means of the headform acceleration maxima for repeat tests were calculated.

Results: Tests on polyethylene foam indicated that an increase in thickness from $10 \mathrm{~mm}$ to $16 \mathrm{~mm}$ would improve headgear performance. These modifications were incorporated in part into two headgear models: the Albion Headpro and the Canterbury brand Body Armour honeycomb headgear. The headgear tests show that significant reductions in headform acceleration were achieved by increasing the foam density and thickness. Mean headform acceleration maxima for the $16 \mathrm{~mm}$ thick modified rugby headgear was about $25 \%$ of that of standard headgear for lateral impact 0.3 and $0.4 \mathrm{~m}$ drop heights and $27 \%$ for the centre front $0.3 \mathrm{~m}$ drop tests. At these impacts, the headform acceleration for the modified rugby headgear was below $200 \mathrm{~g}$.

Conclusions: Significant improvements in impact energy attenuation performance are possible with small design changes. Whether these are sufficient to reduce the rate or severity of concussion in rugby and Australian rules football can only be shown by formal prospective studies on the field.

W earing protective headgear is one method of reducing the risk of head injury in sporting, recreational, occupational, and transport activities. Although no exact figures are available, there has been a gradual increase in the use of protective headgear in rugby union and rugby league over the last decade. In contrast, headgear is little worn in Australian rules football. Debate remains open as to the role of protective headgear, whether it should be designed primarily to reduce superficial head injury or whether it can be designed to reduce the rate and severity of neurological injury.

Since the publication of our laboratory study of protective headgear for football in $2000,{ }^{1}$ we have had the opportunity to implement small design changes to two models of protective headgear manufactured for rugby union, rugby league, and Australian football. Based on poor performance in impact energy attenuation tests, ${ }^{1}$ we concluded that the protective headgear available at that time was unlikely to reduce the risk of concussion or more severe head injury. The study suggested that increases in thickness and/or density of the foam that constitutes the bulk of the headgear may improve performance by reducing the magnitude of the impact force to the head, the head's acceleration, and resultant injury. As foam thickness increases, the potential for work to be performed through the deformation of the foam is also increased, resulting in a greater capacity for the impact force to be reduced by the headgear. This potential is modulated by the foam material type and its density or stiffness. This paper describes the bases for the headgear design changes and how the headgear performed in laboratory tests.

\section{METHODS}

There were two test phases: (a) using foam samples; $(b)$ using the modified headgear. The first phase was conducted to establish the design features for the headgear tested in the second phase. Tests were conducted, using the equipment and methods described by McIntosh and McCrory, ${ }^{1}$ at a National Association of Testing Authorities certified facility. In short, a size $\mathrm{C}$ rigid magnesium alloy headform was used, and acceleration data were captured at $10000 \mathrm{~Hz}$ and filtered with a Channel Class 1000 filter (manufactured by the Roads and Traffic Authority, Crashlab, Sydney, Australia). The Channel Class 1000 filter is a low pass filter with a $1650 \mathrm{~Hz}$ cut off frequency. Headgear and foams were tested at ambient temperature $\left(21^{\circ} \mathrm{C}\right)$.

\section{Phase 1: tests on foam samples}

The impact energy attenuation property of a selection of polyethylene foams was tested. Polyethylene foam is used extensively in the manufacture of protective headgear for football. Foam thickness (10, 12, 14, and $16 \mathrm{~mm}$ ) and density ( 50 and $67 \mathrm{~kg} / \mathrm{m}^{3}$ ) were varied, as was the impact severity by increasing the drop height from 0.2 to $1 \mathrm{~m}$. Increases in drop height increased the impact energy from 9.8 to $39.2 \mathrm{~J}$. The International Rugby Board $(\mathrm{IRB})^{2}$ require testing from a $0.3 \mathrm{~m}$ drop height. There is no headgear performance standard for Australian rules or rugby league football. The impact severity was increased beyond the $0.3 \mathrm{~m}$ drop tests, as it had been shown that concussive impacts in football occurred with impacts equivalent to a drop test of height about $1.0 \mathrm{~m} .^{3}$ Increments in impact severity-that is, $0.1 \mathrm{~m}$ drop height-ceased when the headform acceleration approached $500 \mathrm{~g}$, and no tests were conducted from drop heights greater than $0.8 \mathrm{~m}$. Headform acceleration of about $500 \mathrm{~g}$ exceeds reasonable tolerance levels. ${ }^{4-9}$ The foam samples were placed over a flat steel impact anvil. Foam test samples were square shaped $(300 \times 300 \mathrm{~mm})$. The headform impacted the foam on the frontolateral aspect. Resultant 
headform acceleration time histories and maxima were recorded.

\section{Phase 2: headgear tests}

The Albion Headpro model was specifically manufactured by Albion Hat and Cap Pty Ltd (Sydney, Australia) for the Australian Football Injury Prevention Project (AFIPP). ${ }^{10}$ This model had performed the best in the original laboratory tests. ${ }^{1}$ Owing to budget, time, and manufacturing restrictions, only small design changes were possible and the "look" remained unchanged. The changes included increasing the polyethylene foam density from $45 \mathrm{~kg} / \mathrm{m}^{3}$ to $65 \mathrm{~kg} / \mathrm{m}^{3}$ and extending the coverage of the $2 \mathrm{~mm}$ thick ethylene vinyl acetate insert to include the centre front of the headgear (fig 1). The total thickness increased from 12.5 to $14 \mathrm{~mm}$. Other design changes included changing the colour from black to grey and lengthening the chin strap.

The Canterbury brand honeycomb headgear, manufactured by Body Armour in New Zealand, was modified to assess its performance in rugby union football. The decision was based on our experience in the 1999 pilot study of rugby headgear ${ }^{11}$ in which it was clear that more players, especially those that did not normally wear headgear, are likely to agree to wear the most popular models. The honeycomb model is popular and allowed changes in foam thickness and density without changing the drape of the headgear around the head. It was considered that a large flat plate of foam (as for test phase 1) would not wrap around the head. The Honeycomb model has small, mainly hexagonal shaped, blocks of foam in a fabric base (fig 2). The modified headgear was formed using $16 \mathrm{~mm}$ thick $60 \mathrm{~kg} / \mathrm{m}^{3}$ polyethylene foam, whereas the standard model consists of $10 \mathrm{~mm}$ thick $45 \mathrm{~kg} / \mathrm{m}^{3}$ polyethylene foam.

Impact energy attenuation tests were conducted on the standard Honeycomb model, the modified Albion and Honeycomb models, and a second IRB approved model. The impact tests were conducted so that either the lateral or the centre front aspects of the headgear impacted the anvil (fig l).

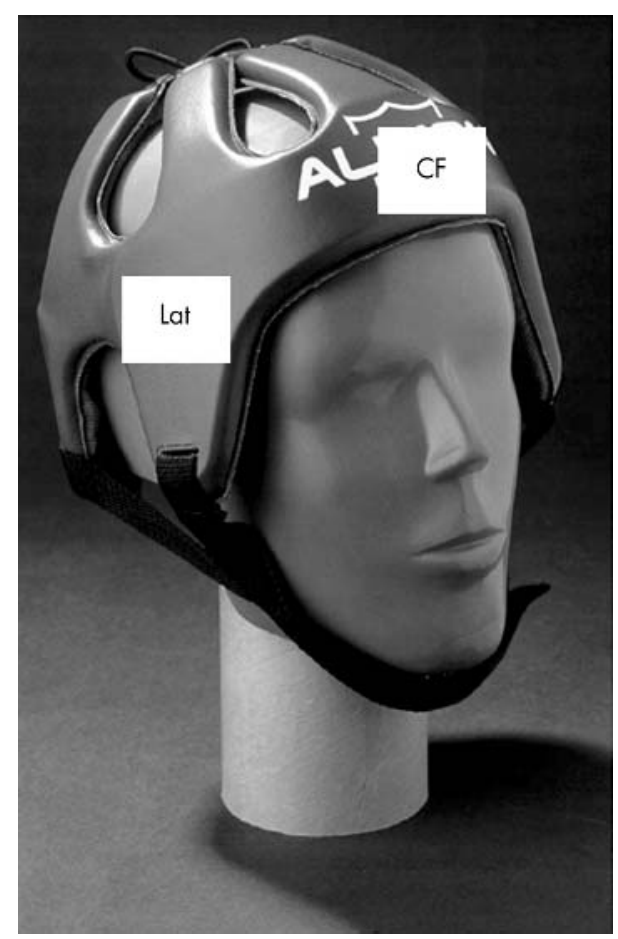

Figure 1 Headpro model. Lat, Lateral impact site; CF, centre front impact site.

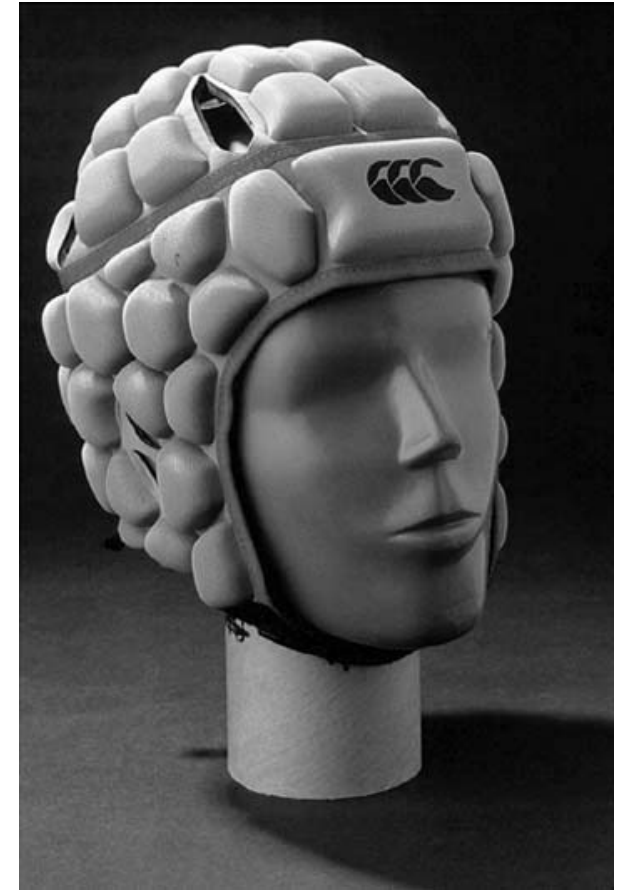

Figure 2 Honeycomb headgear model.

The drop heights tested were 0.3, 0.4, 0.5, and $0.6 \mathrm{~m}$, although in some cases the 0.5 and $0.6 \mathrm{~m}$ tests were discontinued because of the large headform accelerations measured with specific headgear and impact locations. Three tests were conducted per unit from each height and two units were tested per drop height. Resultant centre of gravity headform acceleration time histories and maxima were recorded. The maxima for the first impacts were recorded, as were the means for all tests for each test configuration. These variables were recorded, as they reflect the impact energy attenuation properties of the headgear. ${ }^{1}$ Lower headform acceleration reflects a reduction in the severity of the impact and head injury likelihood.

\section{RESULTS}

\section{Foam tests}

Figure 3 shows a summary of the impact test results for the polyethylene foam. The results show that the thicker the foam the greater the impact energy attenuation (lower maximum resultant headform acceleration) for all drop

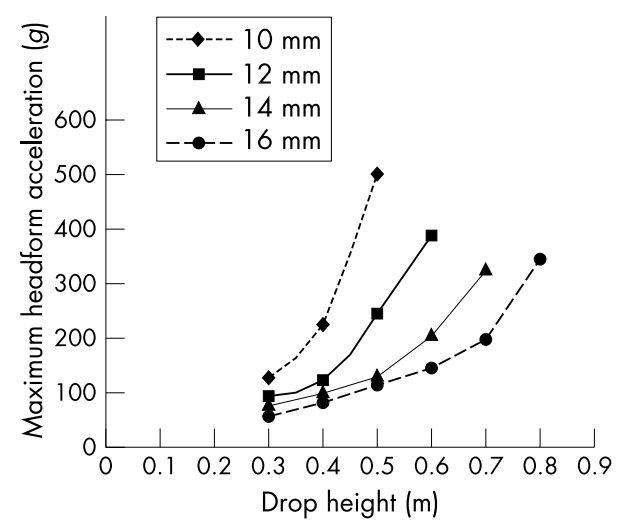

Figure 3 Summary of polyethylene foam impact tests for four thicknesses (10 to $16 \mathrm{~mm}$ ). 
heights. The small changes in density from 50 to $67 \mathrm{~kg} / \mathrm{m}^{3}$ did not alter the acceleration significantly; therefore the average of the two foam densities is presented for $2 \mathrm{~mm}$ increments in thickness from 10 to $16 \mathrm{~mm}$. Foam thicknesses greater than $16 \mathrm{~mm}$ were not tested, as it was thought that the increased stiffness would interfere with manufacturing processes and user comfort. The $16 \mathrm{~mm}$ thick foam appeared to be fully compressed by the $0.8 \mathrm{~m}$ tests and unable to further attenuate the impact energy.

\section{Headgear tests}

Table 1 shows a summary of headform acceleration data for the headgear tests. The results for the standard Albion model and rugby headgear are from tests we conducted in 1999. ${ }^{1}$ New data are for an exemplar IRB certified rugby headgear, the modified Albion, the standard honeycomb, and the modified honeycomb headgear. The resultant centre of gravity headform acceleration maxima for the six tests per drop height were averaged and are presented in table 1 along with the maximum acceleration for the first impact. The maximum acceleration for the first impact is lower than subsequent impacts.

The results show that the mean resultant headform acceleration maxima for the modified honeycomb headgear was $23 \%$ and $27 \%$ of that of standard headgear for the lateral $0.3 \mathrm{~m}$ and centre front $0.3 \mathrm{~m}$ drop tests respectively. If data for the first impacts only were used, the resultant headform acceleration maxima for the modified honeycomb headgear were $25 \%$ and $22 \%$ for $0.3 \mathrm{~m}$ and $0.4 \mathrm{~m}$ lateral impacts respectively and $17 \%$ for the $0.3 \mathrm{~m}$ centre front impact ( $\mathrm{p}=$ 0.005 for all three test configurations; $t$ test). Further statistical analyses were not conducted, as the tests on the standard model were stopped because of the high measured accelerations. Standard Albion Headpro headgear was not available for testing, as its manufacture had been discontinued when the tests were conducted. No statistical comparisons were made between the earlier tests ${ }^{1}$ and the modified Albion Headpro. For the Headpro, the differences between the standard and AFIPP modified helmets were small at the lower drop heights, but there was a noticeable improvement in performance at the 0.5 and $0.6 \mathrm{~m}$ drop heights.

There was a gradual decrease in impact energy attenuation with repeat impacts in quick succession to the same site for all models. This suggests that the foam properties are altered with each impact, making the foam softer. Although the headform's orientation is fixed during the sequence of tests, small changes in the position of the headgear on the headform may also account for variation in the test results.
Centre front impacts resulted in higher headform accelerations than lateral impacts of equivalent severity. Centre front impacts were stopped at $0.4 \mathrm{~m}$ because of the large headform accelerations.

\section{DISCUSSION}

The foam test results show that attenuation of impact energy could be increased by increasing foam thickness. These findings were incorporated into the design of the Honeycomb headgear and Albion Headpro. Both modified models showed significantly greater attenuation of impact energy than other models tested and previous data. The $16 \mathrm{~mm}$ thick Honeycomb headgear model performed significantly better than the $10 \mathrm{~mm}$ standard model. However, the block foam testing results suggested that the improvement could be even greater. Maximum headform accelerations for the tests on the $16 \mathrm{~mm}$ block foam from drop heights of 0.3 and $0.4 \mathrm{~m}$ were 58 and $83 \mathrm{~g}$ respectively compared with 69 and $100 \mathrm{~g}$ for the modified honeycomb headgear. As shown in fig 3, the maximum headform acceleration at a drop height of $0.7 \mathrm{~m}$ is $200 \mathrm{~g}$, whereas for the modified honeycomb headgear, the maximum headform acceleration had exceeded $200 \mathrm{~g}$ between drop heights of 0.4 and $0.5 \mathrm{~m}$. At $0.4 \mathrm{~m}$ and $0.6 \mathrm{~m}$ drop heights, the maximum headform acceleration for the modified headgear was $120 \%$ and $350 \%$ of the block foam results respectively. This discrepancy is probably due to the small pieces of foam in the Honeycomb headgear model compared with the larger foam blocks tested and the related reduction in load distribution and lateral stability. The Albion Headpro is constructed from continuous foam sheets, and its performance was better than the Honeycomb model in the 0.5 and $0.6 \mathrm{~m}$ drop tests. Whereas the modified Honeycomb headgear performed slightly better at the lower drop heights than the modified Albion Headpro, at more severe impacts the Honeycomb model's smaller foam components may reduce its load distributing ability and thus its overall impact energy attenuation performance. The difference in thickness between the two models was also only $2 \mathrm{~mm}$, and the ethylene vinyl acetate component is denser than the polyethylene part. When the shape and size of the foam components are determined, consideration must be given to fit, mass, comfort, and ventilation. The test results indicate that incorporating larger sheets of foam in headgear over common head impact sites may offer impact performance advantages - that is, a hybrid of the Headpro and honeycomb headgear models.

Impacts to the centre front on all headgear resulted in greater headform accelerations than lateral impacts of equivalent severity. This is probably due to more localised

Table 1 Summary of maximum resultant headform acceleration for first impact (in bold) and mean maximum resultant headform acceleration for six repeat impacts (in parentheses) for lateral and centre front impacts. Acceleration is in gravities

\begin{tabular}{|c|c|c|c|c|c|c|}
\hline \multirow{2}{*}{$\begin{array}{l}\text { Drop height }(\mathrm{m}) \\
\text { and velocity }(\mathrm{m} / \mathrm{s})\end{array}$} & \multirow{2}{*}{$\begin{array}{l}\text { Mclntosh \& } \\
\text { McCrory' } \\
\text { (mean of rugby } \\
\text { ) union models) }\end{array}$} & \multirow{2}{*}{$\begin{array}{l}\text { Rugby union } \\
\text { model (2002) } \\
\text { (standard) }\end{array}$} & \multicolumn{2}{|c|}{$\begin{array}{l}\text { Canterbury brand } \\
\text { honeycomb headgear by } \\
\text { Body Armour }\end{array}$} & \multicolumn{2}{|c|}{ Albion Headpro } \\
\hline & & & Standard & Modified & Standard' & Modified \\
\hline \multicolumn{7}{|l|}{ Lateral impacts } \\
\hline $0.3(2.4)$ & 336 & $234(346)$ & 276 (399) & $69(91)$ & 114 & $83(94)$ \\
\hline $0.4(2.8)$ & 449 & - & $494-$ & $110(165)$ & 141 & $134(165)$ \\
\hline $0.5(3.1)$ & - & - & - & $387(520)$ & 482 & 171 (231) \\
\hline $0.6(3.4)$ & - & - & - & 516 (623) & 524 & 370 (577) \\
\hline \multicolumn{7}{|l|}{$\begin{array}{l}\text { Centre front } \\
\text { impacts }\end{array}$} \\
\hline $\begin{array}{l}0.3(2.4) \\
0.4(2.8)\end{array}$ & $\begin{array}{l}\text { No original } \\
\text { data' }\end{array}$ & $\begin{array}{l}\text { No data } \\
\text { collected }\end{array}$ & $\begin{array}{l}689(714) \\
-\end{array}$ & $\begin{array}{l}123(191) \\
273(436)\end{array}$ & $\begin{array}{l}\text { No original } \\
\text { data' }\end{array}$ & $\begin{array}{l}206(323) \\
326(506)\end{array}$ \\
\hline
\end{tabular}

In the standard and modified forms of the Honeycomb headgear the foam was 10 and $16 \mathrm{~mm}$ thick respectively. -, Test series stopped because of large headform accelerations. 
loading caused by the headform curvature in the centre front region. In contrast, lateral impacts were against a relatively flat section of the headform. This again is of importance with regard to the size of the foam blocks and the contours of the underlying skull.

Resultant centre of gravity headform acceleration increases with each repeat impact. This is a greater problem on more severe impacts. Further testing is required to examine this characteristic as well as the influence of temperature and wetness on impact energy attenuation performance.

Although there is a continuing debate on the relation between the magnitude of biomechanical variables, such as headform acceleration, and head injury risk, the thicker headgear reduced headform acceleration to less than $200 \mathrm{~g}$ for the 0.3 and $0.4 \mathrm{~m}$ impacts. This is a substantial improvement over the performance of other models and suggests that the headgear is more likely to reduce head injury. ${ }^{13} 11$

The laboratory tests show that large improvements in performance can be achieved by small modifications to standard designs. Randomised controlled trials, such as AFIPP, will help to determine whether headgear modifications result in significant reductions in neurological head injury during sport. However, the improvements in impact energy attenuating performance may not be sufficient to reduce concussion for several reasons: the impacts may be more severe than simulated in the laboratory tests; ${ }^{3}$; players who wear headgear may play more aggressively and therefore expose themselves to more severe impacts; the stiffer thicker headgear may be too uncomfortable to be a viable alternative.

\section{ACKNOWLEDGEMENTS}

We thank the Victorian Health Promotion Foundation and the NSW Sporting Injuries Committee for financial support. The support and assistance of Albion and Body Armour were greatly appreciated. There is no conflict of interest as funding was not received from either headgear manufacturer, and none of the authors has a professional or business affiliation with either manufacturer.

\section{Authors' affiliations}

A McIntosh, C F Finch, University of New South Wales, Sydney,

Australia

P McCrory, University of Melbourne, Melbourne, Australia

\section{REFERENCES}

1 McIntosh AS, McCrory P. Impact energy attenuation performance of football headgear. Br J Sports Med 2000;34:337-41.

2 IRB. Law 4M-98g: standard performance specification for specific items of players' clothing.

3 McIntosh AS, McCrory P, Comerford J. Head impact dynamics of concussion in rugby and Australian rules football. Med Sci Sports Exerc 2000;32:1980-4.

4 Mclntosh A, Kallieris D, Mattern R, et al. Head and neck injury resulting from low velocity direct impact. Proceedings of the 37th STAPP Car Crash Conference. Warrendale, PA: Society of Automotive Engineers, 2000:SAE 933112.

5 Mclntosh A, Kallieris D, Mattern R, et al. An evaluation of pedal cycle helmet performance requirements. Proceedings of the 39th STAPP Car Crash Conference. Warrendale, PA: Society of Automotive Engineers, 1995.

6 Hirsch A, Ommaya A. Protection from brain injury: the relative significance of translational and rotational motions of the head after impact. Proceedings of the 14th Stapp Car Crash Conference. Warrendale, PA: Society of Automotive Engineers, 1970:144-151.

7 Newman J. Head injury criteria in automotive crash testing. Proceedings of the 24th Stapp Car Crash Conference. Warrendale, PA: Society of Automotive Engineers, 1980:701-747.

8 Nusholtz G, Lux $\mathrm{P}$, Kalker $\mathrm{P}$, et al. Head impact response: skull deformations and angular accelerations'. Proceedings of the 28th Stapp Car Crash Conference. Warrendale, PA: Society of Automotive Engineers, 1984:41-75.

9 Allsop DL, Peri TR, Warner CY. Force/deflection and fracture characteristics of the temporo-parietal region of the human head. Proceedings of the 35th Stapp Car Crash Conference. Warrendale, PA: Society of Automotive Engineers, 1991.

10 Finch C, Mclntosh AS, McCrory P. What is the evidence base for the use of protective headgear and mouthguards in Australian football? Sport Health 2000:35-7.

11 Mclntosh AS, McCrory P. Effectiveness of headgear in under 15 rugby union football' Br J Sports Med 2001;35:167-9.

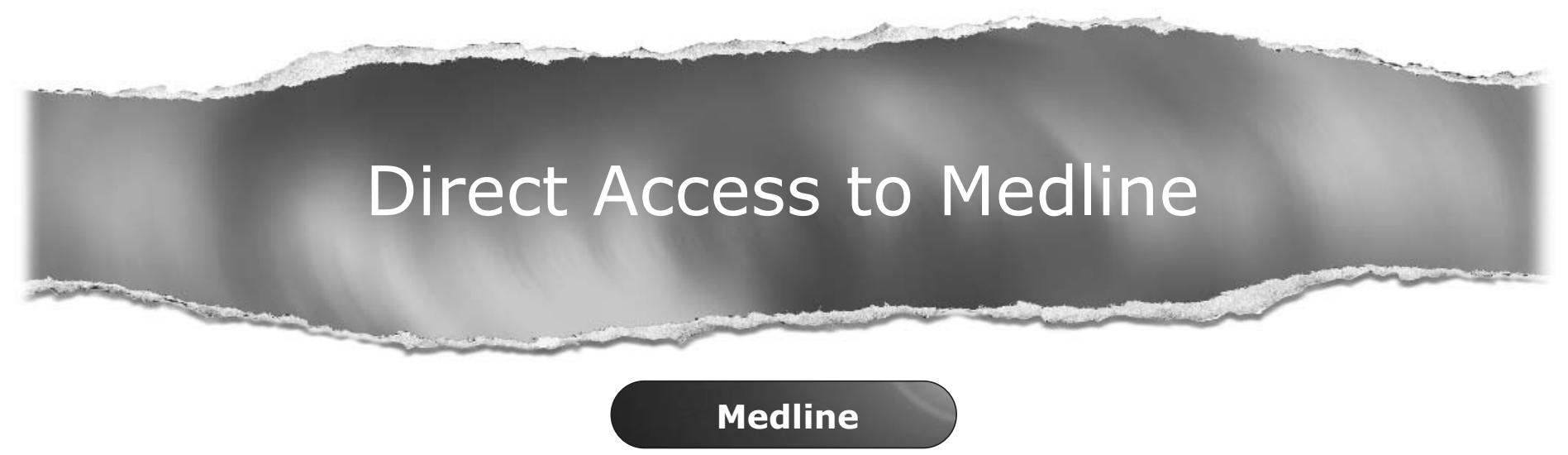

Link to Medline from the homepage and get straight into the National Library of Medicine's premier bibliographic database. Medline allows you to search across 9 million records of bibliographic citations and author abstracts from approximately 3,900 current biomedical journals.

\section{www.bjsportmed.com}

